\title{
Factors influencing pain therapy for metastatic cancer patients in Bosnia and Herzegovina
}

\author{
Ivana Tica Sedlar ${ }^{1}$, Sanda Čale ${ }^{1}$, Ana Parić ${ }^{1}$, Marija Perić $^{1}$, Jasna Jurčić ${ }^{1}$, \\ Eduard Vrdoljak ${ }^{2}$
}

${ }^{1}$ Department of Oncology, University Hospital Mostar, Mostar, Bosnia and Herzegovina, ${ }^{2}$ Center of Oncology University Hospital Split, Split, Croatia

\author{
Correspondence: \\ tica1978@gmail.com \\ Tel.: + 385989012306 \\ Fax.: + 38536336464
}

Received: 10 February 2016

Accepted: 24 August 2016

Key words: Pain • Cancer • Analgesics.

\begin{abstract}
Objective. To investigate cancer pain management and evaluate factors that could be addressed and lead to potential improvement of pain therapy. Materials and methods. Two hundred patients with metastatic cancer pain at the Department of Oncology, University Hospital Mostar, completed questionnaires about cancer pain treatment. Thirty oncologists from the Cancer Institute, University of Sarajevo and the Department of Oncology, Clinical Hospital, Mostar were asked to complete the questionnaire about cancer pain management. Results. Compliance for analgesics was statistically better $(\mathrm{p}=0.013)$ for patients who were regularly asked about pain than for those patients who were asked periodically. Nearly twice as many patients, whom the doctor always asked about pain, regularly took medication $(65.5 \%$ versus $32.8 \%$ ). There was a statistically significant, positive relationship between regular use of analgesics and the interest of the doctor about pain reduction after initiation of analgesic therapy $(p=0.008)$. Almost half of the patients, $47 \%$, stated that their doctor did not devote enough time to their pain problems during the interview. Statistically significantly more patients took analgesic medication regularly if they were not afraid of narcotics $(\mathrm{p}=0.006)$. Numerical or VAS scales in description of cancer pain were used by only $30 \%$ of interviewed oncologists. The vast majority of doctors, $86.7 \%$, used opiates for the terminal phase of the illness. Conclusion. Assessment and the treatment of cancer pain in Bosnia and Herzegovina remains inadequate, emphasizing the need for changes to cancer pain patient care.
\end{abstract}

\section{Introduction}

Unfortunately cancer has become a major public health problem and an increasingly important factor in the burden of disease. Based on the most recent available data for 2012, there were an estimated 3.45 million new cases of cancer (excluding non-melanoma skin cancer) and 1.75 million deaths from cancer in Europe $(1,2)$. Cancer pain is a multifactorial phenomenon that results in complex interactions between physical, psychological, cognitive, social and other factors. The prevalence of acute and chronic pain in cancer patients is high: about $30 \%$ in patients with newly diagnosed cancer, $50-70 \%$ in patients receiving active anticancer therapy, and 60-80\% in patients with advanced disease (35). Untreated and poorly treated pain affects physical and mental health, functional status 
and quality of life, and is associated with an increased incidence of medical complications, increased use of medical services, decreased patient satisfaction, and unnecessary suffering (5-9).

A decrease in the intensity of the pain is one of the fundamental tasks in clinical practice, so identification of factors that influence the outcome of pain treatment is of great importance for improving the quality of life of cancer patients. It has been shown that pain can be controlled in close to $90 \%$ of patients when proper guidelines for pain management are used (10). Unfortunately, despite universal advances in cancer-pain management through better anticancer therapy in general and better pain management as well, there is widespread evidence that cancer pain remains inadequately treated (11-13).

Inadequate treatment of cancer pain is often caused, especially in countries in development, by barriers to the use of analgesics, opioids in particular (14). In this respect, patient, health care professional-related and institutional barriers have been identified (15-22). The most significant patient-related barriers are the patient's reluctance to report pain and adhere to treatment recommendations (15).

Effective doctor-patient communication is the cornerstone of successful pain treatment; however, poor communication between patients and their physicians remains a pervasive problem (16). Several studies have investigated cancer patients' communication with healthcare providers concerning their pain experience (17-20). Few of these studies have focused on the quality of the communication between cancer patients and physicians regarding the subject of the patient's pain. The quality of the patientphysician communication was not satisfactory in general (17-20). Patients want to be more active in the process of information exchange by expressing their own needs; they also want their providers to have better communication skills and to address their fears regarding cancer pain management as well.

Insufficient knowledge and education of physicians in cancer pain management has been regarded as one of the main factors causing inadequate pain relief in cancer patients all over the world (21). There are institutional barriers in many countries, such as complicated bureaucratic regulations governing the supply, regulations on prescription and administration of opioids, as well as problems related to continuity of care, when the patient is seen by a number of different physicians, across a number of different health care settings, with no one capable or willing to take responsibility for the overall pain management (22). Furthermore, it has been shown that changes to legal requirements concerning opioid prescription have had less influence on the outcomes of pain treatment, if compared with patient or physician-related barriers (23).

Although there have been numerous studies on the topic of quality of treatment of pain in various countries of the world, this is the first study in the area of Bosnia and Herzegovina, whose poor socio-economic situation in general contributes to poorer health care for patients, compared to developed countries. In most parts of Bosnia and Herzegovina patients must buy analgesics, which hinders correct medical decisions when prescribing analgesics for pain. Also, an additional problem is the lack of an adequate number of clinics for pain treatment, which makes it difficult for oncologists in specific oncological treatment.

The aim of this study was to describe the current state of cancer pain management in Bosnia and Herzegovina, and to identify barriers that may be contributing to improper pain management. Additionally, our goal was to compare cancer-related pain control between compliant and non-compliant pa- 
tients, in order to provide new guidelines for pain management in Bosnia and Herzegovina, since this could have a significant impact on the quality of life of cancer patients and give physicians directions in their future practice.

\section{Materials and methods}

\section{Study design}

This was a non-interventional study of 200 metastatic cancer patients ( 88 females and 112 males) with cancer pain who were treated at the Department of Oncology, University Hospital, Mostar in the period from September 2011 to April 2012. In the same time interval the oncologists who treated these patients at the same Department ( 8 oncologists) as well as oncologists from the largest cancer institution in Bosnia and Herzegovina, The Cancer Institute, University of Sarajevo (22 oncologists), were given questionnaires about pain management. The questionnaire used in this study was adapted from the questionnaire used to test the quality of pain treatment in Ankara, Turkey. The adapted questionnaire was validated and translated to Croatian and back translated to English. In the appendix of this study are the questionnaires for patients and doctors that were used in study.

\section{Participants}

The predefined inclusion criteria for patients were as follows: age $>18$ years, diagnosed with metastatic cancer and existence of cancer pain. None of the patients refused to participate in the research. Patients were screened to determine whether they met the inclusion criteria. They were provided with study information, and after the patients consented, we enrolled them in the study. The patients' data were marked with a code, and anonymous patient data were collected and analyzed.

\section{Questionnaire}

The patient questionnaire covered the socioeconomic characteristics of the patients, including age, gender, marital status, number of children, education level, number of household members, and personal monthly income. The "extended family" was regarded as a patient living with children and parents / with children and husband-wife / with husband-wife and parents. Also, the questionnaire covered the level of satisfaction with the information received from doctors about pain, its causes and treatment, the type of analgesic therapy they received, availability of analgesics, satisfaction with treatment, physical and mental state after prescribed therapy, fear of morphine preparations and the most common reason for stopping taking analgesics.

The patient's compliance (regularity of analgesic usage) was determined in relation to gender, education, family monthly income and the number of family members. Concerning questions about pain, patients were asked whether their doctor asked them about pain, if they reported pain, how much time the doctor spent with them talking about pain, if the doctor used instruments for pain measurement, whether the analgesics were free or if doctors asked them about pain relief after pain treatment. Additionally, patients were asked about side effects, fear of analgesic addiction and satisfaction about pain management.

In the oncologists' questionnaires we asked these questions: the usage of instruments for pain measurement, preferred analgesics for treatment of strong, medium and weak pain, the influence of the poor economic situation on the choice of analgesic treatment, the availability of analgesics, the level of knowledge about the treatment of the pain, the importance of training in the treatment of the pain, their relationship to morphine preparations, and the existence of centers for pain treatment. 


\section{Ethics statement}

The study was approved by the Ethics Committee of the School of Medicine in Mostar.

\section{Statistical analysis}

For data processing we used Excel 2000 (Microsoft, USA) and SPSS Statistics 16.0 (IBM, USA). A Kolmogorov-Smirnov test confirmed the normal distribution of data. To compare two sets of numeric data, an appropriate parametric test (student t-test) was used. Qualitative and quantitative data were processed by the appropriate measurement scales(nominal and ordinal) and analyzed using the chi-squared test. To view the results of the survey we used methods of relative numbers, such as percentages and proportions. Statistically significant values were defined as $\mathrm{p}<0.05$.

\section{Results}

The characteristics of the 200 patients included in the study are shown in Table 1.

The median age of patients who regularly took medication was 59.5 years (min-max 44-79 years) and this was higher than in the group of patients who did not regularly take medication, whose median age was 56 years (min-max 31-70 years) ( $\mathrm{p}=0.032$ ).

The results of the patients' questionnaire in terms of compliance to analgesic therapy are shown in Table 2.

One hundred and sixteen (58\%) patients regularly took medication. There was statistically positive correlation between patients who reported pain during the interview with doctors and regularity of taking medication ( $p=0.023)$ : In the group of patients who regularly used medication, 96 patients $(82.8 \%)$ reported pain during the interview with a doctor, while only 20 patients $(17.2 \%)$ did not reported pain during the same interview. Twice as many patients $(n=76,65.5 \%)$,
Table 1 The characteristics of patients enrolled in the study

\begin{tabular}{ll}
\hline Characteristics & \\
\hline Total $(\mathrm{n})$ & 200 \\
Median age (years; min-max) & $58.5(31-79)$ \\
\hline Gender, $\mathrm{n}(\%)$ & $112(56)$ \\
\hline Male & $88(44)$ \\
Female & \\
\hline Who do you live with, $\mathrm{n}(\%)$ & $12(6)$ \\
\hline Alone & $38(19)$ \\
With children & $60(30)$ \\
With husband/wife & $12(6)$ \\
With parents & $78(39)$ \\
With extended family & \\
\hline Education level, $\mathrm{n}(\%)$ & $94(47)$ \\
\hline Elementary school & $84(42)$ \\
High school & $22(11)$ \\
\hline University & \\
\hline Personal monthly financial income, $\mathrm{n}(\%)$ & $10(2)$ \\
\hline No allowances & $132(66)$ \\
$<500$ EUR & $54(27)$ \\
$500-1500$ EUR & 1500 EUR \\
\hline
\end{tabular}

whose doctors always asked about pain, were taking analgesics regularly $(\mathrm{p}<0.001)$ in comparison to the patients whose doctors never asked about pain. In terms of whether the doctor used a scale for pain measurement, only 18 patients reported that the doctor used this scale, while 182 did not $(\mathrm{p}=0.026)$. Also, there is a statistically significant relationship between analgesic compliance and when oncologists asked cancer patients about the reduction in the intensity of the pain after administration of analgesic in further interviews $(\mathrm{p}<0.001)$ : when the doctor asked patients about cancer pain relief after administration of analgesics 108 patients took them regularly (93.1\%). Only 8 patients (6.9\%) took analgesics regularly if the doctor did not ask about the cancer pain relief after ordination of pain therapy. 
Table 2 Results of the metastatic cancer patients' questionnaire according to compliance to analgesic therapy

\begin{tabular}{|c|c|c|c|c|c|}
\hline \multirow{3}{*}{ Question } & & \multirow{3}{*}{$\begin{array}{l}\text { All } \\
\text { patients } \\
n=200\end{array}$} & \multicolumn{2}{|c|}{ Regularity of taking drug } & \multirow{3}{*}{$\mathrm{p}^{*}$} \\
\hline & & & Yes & No & \\
\hline & & & $\mathrm{n}=116$ & $\mathrm{n}=84$ & \\
\hline \multirow{3}{*}{ Was your doctor interested in your pain? } & Always & 106 & $76(65.5)$ & $30(35.7)$ & \multirow{3}{*}{$<0.001$} \\
\hline & Sometimes & 90 & $38(32.8)$ & $52(61.9)$ & \\
\hline & No interest & 4 & $2(1.7)$ & $2(2.4)$ & \\
\hline \multirow{2}{*}{ Have you reported pain during the interview? } & Yes & 154 & $96(82.8)$ & $58(69)$ & \multirow{2}{*}{0.023} \\
\hline & No & 46 & $20(17.2)$ & $26(31)$ & \\
\hline \multirow{2}{*}{$\begin{array}{l}\text { Did your doctor have enough time during the } \\
\text { conversation with you? }\end{array}$} & Yes & 106 & $68(58.6)$ & $38(45.2)$ & \multirow{2}{*}{0.061} \\
\hline & No & 94 & $48(41.4)$ & $46(54.8)$ & \\
\hline \multirow{2}{*}{$\begin{array}{l}\text { Did your doctor use } \\
\text { a scale for pain measurement? }\end{array}$} & Yes & 18 & $6(5.2)$ & $12(14.3)$ & \multirow{2}{*}{0.026} \\
\hline & No & 182 & $110(94.8)$ & $72(85.7)$ & \\
\hline \multirow{2}{*}{$\begin{array}{l}\text { Did your doctor inform you about analgesic side } \\
\text { effects? }\end{array}$} & Yes & 86 & $56(48.3)$ & $30(35.7)$ & \multirow{2}{*}{0.077} \\
\hline & No & 114 & $60(51.7)$ & $54(64.3)$ & \\
\hline \multirow{2}{*}{ Were analgesics free of charge? } & Yes & 78 & $50(43.1)$ & $28(33.3)$ & \multirow{2}{*}{0.162} \\
\hline & No & 122 & $66(56.9)$ & $56(66.7)$ & \\
\hline \multirow{5}{*}{$\begin{array}{l}\text { How much did they cost per month } \\
\text { of therapy (EUR)? }\end{array}$} & $<10$ & 52 & $26(22.4)$ & $26(31)$ & \multirow{5}{*}{0.215} \\
\hline & 10- 4 & 50 & $32(27.6)$ & $18(21.4)$ & \\
\hline & $25-34$ & 12 & $6(5.2)$ & $6(7.1)$ & \\
\hline & $35-49$ & 6 & $2(1.7)$ & $4(4.8)$ & \\
\hline & $>50$ & 2 & $0(0)$ & $2(2.4)$ & \\
\hline \multirow{2}{*}{ Were you prescribed analgesic relief pain? } & Yes & 120 & $74(63.8)$ & $46(54.8)$ & \multirow{2}{*}{0.198} \\
\hline & No & 80 & $42(36.2)$ & $38(45.2)$ & \\
\hline \multirow{2}{*}{$\begin{array}{l}\text { Was the doctor interested in the reduction in } \\
\text { pain after treatment with analgesics? }\end{array}$} & Yes & 168 & $108(93.1)$ & $60(71.4)$ & \multirow{2}{*}{$<0.001$} \\
\hline & No & 32 & $8(6.9)$ & $24(28.6)$ & \\
\hline \multirow{2}{*}{$\begin{array}{l}\text { Were you afraid of addiction to prescribed pain } \\
\text { medication? }\end{array}$} & Yes & $80(40.0)$ & $32(27.6)$ & $48(57.1)$ & \multirow{2}{*}{$<0.001$} \\
\hline & No & 120 & $84(72.4)$ & $36(42.9)$ & \\
\hline
\end{tabular}

Data are absolute frequencies $(\%) ;{ }^{*} \times 2$ test.

Mostly due to the shortness of the interview and poor communication, 94 patients (47\%) said that they were not able to inform the doctor clearly about their pain (Table 2 ). Eighty-four patients (42\%) were taking analgesics irregularly because of fear of the adverse effects, they did not believe in the effect of the drug, or they did not believe in it because the drug did not work effectively from the start, so they did not continue taking the medication. Sixty-one percent of patients had to buy the medication, but this did not affect the regularity of taking it $(\mathrm{p}=0.162)$. Almost twice (1.7 times) as many patients who were not afraid of becoming addicted to analgesics were in the group of patients who regularly took medication, compared to those patients who did not regularly take them. There were twice as many of those who were afraid of addiction to drugs in the group of those who did not use analgesics regularly $(\mathrm{p}<0.001)$.

All the other data about the doctors' questionnaires about pain can be found in Table 3. Twenty-one doctors (70\%) had more than five years' work experience, and nineteen believed that the poor economic situation in the country had a great influence on pain 
Table 3 Results of the oncologists' questionnaire about pain treatment

\begin{tabular}{|c|c|c|}
\hline Question & & All doctors $(n=30)$ \\
\hline \multirow[t]{2}{*}{ Price of analgesics } & Asked patients of the possibility of paying & $22(73.3)$ \\
\hline & Did not ask about payment & $8(26.7)$ \\
\hline \multirow[t]{4}{*}{ Most commonly used analgesics } & NSAR & $17(56.7)$ \\
\hline & Paracetamol & $4(13.3)$ \\
\hline & Tramadol & $8(26.7)$ \\
\hline & Fenacetin & $1(3.3)$ \\
\hline \multirow{3}{*}{$\begin{array}{l}\text { Preferred form of administration of } \\
\text { opioids }\end{array}$} & Oral & $19(63.3)$ \\
\hline & Transdermal & $9(30)$ \\
\hline & Other & $2(6.6)$ \\
\hline \multirow[t]{2}{*}{ Need for free analgesics } & Yes & $27(90)$ \\
\hline & No & $3(10)$ \\
\hline \multirow[t]{2}{*}{ Use of adjuvant drugs } & Yes & $26(86.7)$ \\
\hline & No & $4(13.3)$ \\
\hline \multirow{2}{*}{$\begin{array}{l}\text { How often do you ask patients about } \\
\text { pain? }\end{array}$} & Always & $22(73.3)$ \\
\hline & Sometimes & $8(26.7)$ \\
\hline \multirow[t]{3}{*}{ Methods of measuring pain } & Do not use instruments to measure pain & $21(70)$ \\
\hline & VAS scale & $2(6.7)$ \\
\hline & Numerical scale & $7(23.3)$ \\
\hline \multirow{2}{*}{$\begin{array}{l}\text { Interested about pain reduction after } \\
\text { ordination of analgesics }\end{array}$} & Always & $27(90)$ \\
\hline & Sometimes & $3(10)$ \\
\hline \multirow{2}{*}{$\begin{array}{l}\text { Satisfaction with existing education about } \\
\text { pain }\end{array}$} & No & $26(86.7)$ \\
\hline & Yes & $4(13.3)$ \\
\hline \multirow{4}{*}{$\begin{array}{l}\text { How much time has passed since your last } \\
\text { education about pain management? }\end{array}$} & $<6$ months & $5(16.7)$ \\
\hline & $6-12$ months & $7(23.3)$ \\
\hline & $>12$ months & $14(46.7)$ \\
\hline & I've never had any education about pain treatment & $4(13.3)$ \\
\hline
\end{tabular}

Data are absolute frequencies (\%); NSAR=Non steroid Anti-rheumatic Drugs; VAS=Visual analogue scale.

treatment of cancer patients. Twenty-six doctors (86.7\%) preferred administration of opioids (fentanyl, buprenorphine) only in the terminal phase of the disease, when other analgesics were not effective. Numerical or VAS scales for pain measurement were used by only 9 (30\%) doctors. Twenty-two doctors $(73.3 \%)$ reported that they always educated patients about pain and treatment, while 8 physicians (26.7\%) educated them only periodically. Seventy percent of doctors believed that brochures were the best way to educate patients about pain, while $23 \%$ preferred oral or written forms of patient edu- cation. Nearly half of the physicians (46.7\%) had been trained and educated on the subject of pain management for a period of time which lasted over a year, while $40 \%$ had finished their most recent training within one year of completing the questionnaire. On the other hand, $13.3 \%$ of doctors had never had any education on the subject of cancer pain management.

\section{Discussion}

Despite the fact that many types of cancer are now diagnosed early and treated successfully, unfortunately there are still large 
numbers of cancer patients, especially with metastatic disease, who suffer from pain associated with cancer $(3,4)$. Among European countries, wide differences in the quality of oncology care are observed, especially when comparison is made between «old» and «new» EU members, or between developed and developing countries (24). The cancer problem in general, and cancer pain management in particular, is the worst and fastest growing among transitional and middle income countries, and consequently cancer survival is significantly lower in transitional European countries than in the developed ones (24). While there have been numerous studies in various countries of the world on the subject of quality of the pain treatment in cancer patients, the factors that make treatment of pain inadequate and studies from transitional, developing countries are still lacking. This is the first study on the subject of cancer pain management carried out in the territory of Bosnia and Herzegovina. Barriers that hinder adequate pain treatment are classified as barriers related to health care professionals, patients and the health care system $(8,15,21)$. The most common barriers to adequate pain treatment relating to patients and doctors are poor communication and fear of opioids (15). Similarly, in our study, $47 \%$ of patients had the opinion that their conversation regarding the causes and treatment of pain with their doctor did not last long enough. Most patients attributed this problem to the length of time which doctors dedicate to patients, which leads to the fact that half of the patients are not familiar with the cause of the pain they are suffering from. Quality of communication did impact compliance with the prescribed analgesics, as we found that there were twice as many compliant patients in the group whose doctor always asked about pain.

It is interesting to mention that in the group of patients who regularly used medi- cation, 96 patients $(82.8 \%)$ reported pain during the interview with a doctor, while only 20 patients (17.2\%) did not report pain during the same interview. According to the results of the study by Anderson et al. concerning doctor-patient communication, patients testified that $93 \%-100 \%$ of doctors had asked about the presence of the pain, which is not the case in our study, where only $53 \%$ of patients stated that their doctor had asked them about the presence of pain (17). The reason why our results are worse probably lies in the fact that there is only a small number of oncologists, who care for a large number of patients. Moreover, the primary focus of most oncologists is often on the treatment of the cancer, which often results in lower commitment to supportive medicine in general, including pain treatment. Besides this, other possible reasons are the lack of proper education in cancer pain management, the lack of cancer pain clinics and adequate multidisciplinary work, the limited availability of analgesic drugs, and the negative opinion of society in general about narcotic drugs, and social and cultural barriers in general. Patients are often denied adequate medication for pain due to fear of opioids among physicians, nurses, patients and family members (25). Coward and his colleagues found that most patients do not take regular medication because of fear of opioids (19), which is similar to our results, where we found a statistically and clinically significant correlation between the regularity of taking analgesics and fear of opioids. Knowledge of the principles of medical pain treatment among physicians varies greatly in different countries of the world, from $25 \%-30 \%$ to almost $100 \%(26,27)$.

Oncologists are generally poorly educated when it comes to the administration of opioid analgesics. In line with this, our doctors used a scale for pain measurement only in 18 out of 200 patients. Studies show that physicians in Western Europe have bet- 
ter knowledge about opioid analgesics than their counterparts in the southern parts of Asia (28). In a study by Peker at al. (29) they showed that education is a substantial problem in cancer pain management in Turkey, where only $35 \%$ of doctors had some form of pain management education during their residency training. Similarly, in our study, only slightly more than $10 \%$ of the oncologists interviewed considered their pain care education adequate.

In many countries, as is the case in Bosnia and Herzegovina, institutional barriers, such as the intricate bureaucratic regulations related to distribution and administration of opioids, create barriers to effective analgesic care $(22,23)$. Unfortunately, in most counties of Bosnia and Herzegovina, patients are not covered by insurance for the majority of analgesic drugs, particularly transdermal opioids (buprenorphine, fentanyl). All of this creates a major obstacle in the medical decision-making process when prescribing adequate analgesics, or limits the freedom of doctors in good clinical practice in the treatment of pain. According to our research, $60 \%$ of patients had to buy medicine themselves and therefore most doctors prescribe analgesics with the financial background of the patients in mind. All doctors believe that the unsatisfactory socio-economic situation of the country greatly affects the quality of treatment of pain, and that one of the first steps in the improvement of pain treatment should be the introduction of a free analgesics list. It is considered to be of great importance to note the need to organize a pain treatment clinic, as suggested by oncologists, for these do not exist in any institution where the study was conducted.

Although the World Health Organization has had a tremendous impact in changing policies relating to cancer pain management, still in many parts of the world even simple analgesics, particularly morphine, are not available for cancer pain $(17,30,31)$, which is also visible from the results of our survey. It is worth noting that Bosnia and Herzegovina is at the bottom of European opiate consumption for morphine $(0.6750$ $\mathrm{mg} /$ per capita) compared to the neighboring country Croatia (2.6303 mg/per capita) or a developed country such as Denmark (55.9 mg /per capita) (32).

It is essential in each country to determine the severity of barriers to the effective treatment of cancer pain, and to set priorities for their elimination, in order to improve the treatment of cancer pain and to create the conditions for implementation of guidelines for the treatment of pain, which unfortunately we do not have in Bosnia and Herzegovina.

\section{Limitation of study}

A potential limitation of our study was the relatively small absolute number of patients and oncologists included in research. Nevertheless, this is a relatively high number for a small country like Bosnia and Herzegovina, especially when the number of oncologists considered, since more than 50\% of the country's oncologists were enrolled in the study. Also, in our research we used the questionnaire only to define the patients' satisfaction with the quality of pain therapy and compliance to the therapy, and not other methods to check adherence to pain therapy. Many methods have been used to measure adherence, each of which is limited by biases and methodological flaws (33). The potential effect of the measurement itself, termed the "Hawthorne effect," must be considered (34, 35 ). This is the effect (often beneficial or positive) on the outcome of observation itself.

\section{Conclusion}

Between patients who regularly take medication and those that do not, we did not find any statistically significant difference in terms of gender, education, monthly income, 
nor in terms of the number of members in the household. In the group of patients that the doctor always asks about pain, almost twice as many take regular therapy for pain, so doctors need to focus on this important part of therapy. Information about the regularity of the use of analgesics in patients treated for malignant diseases indicates the need for better cooperation between doctors and patients $(47 \%$ of patients reported that their doctor did not have enough time for the conversation about pain therapy). Therefore, state policies should aim to increase the number of oncologists in Bosnia and Herzegovina. This would give oncologists more time to spend with their patients, which would increase patient compliance in pain management. Since no uniform guidelines about pain management in our country exist, they should be drawn up in order to help oncologists in their everyday practice. In order to establish uniform guidelines, doctors need to have better education about the treatment of cancer pain. This can be achieved through the organization of pain clinics, which would be accessible and available to cancer patients. Additionally, basic analgesics should be freely available on the general hospital list to all patients suffering from cancer. We recommend that lectures related to pain management in cancer patients should be included in the curriculums of all Medical Schools, and be part of physicians' training in all training establishments in Bosnia and Hercegovina.

\section{What is already known on this topic}

The first pain clinic was established in 1961 in the USA. Pain clinics are an important part of health care, specialized in pain management. Among European countries wide differences are observed in the quality of oncology care, especially when a comparison is made between developed and developing countries. Cancer pain management is worst, but the fastest growing among transitional and middle income countries. In many countries, as is the case in Bosnia and Herzegovina, institutional barriers, such as the intricate bureaucratic regulations related to distribution and administration of opioids, hinder effective analgesic care. This is the first study about pain man- agement in Bosnia and Herzegovina. Pain clinics in Bosnia and Herzegovina mostly employ only physicians and nurses. Many treatments available in the pain clinics analyzed are not evidence-based.

\section{What this study adds}

According to results from our study we need better pain management in our country through education of doctors, organization of pain clinics and free analgesics available on the general hospital list.

Authors' contributions: Conception and design: ITS and EV; Acquisition, analysis and interpretation of data: SC, MP, AP, JJ, ITS and EV; Drafting the article: ITS and EV; Revising it critically for important intellectual content: EV; Approved final version of the manuscript: ITS.

Conflict of interest: The authors declare that they have no conflict of interest.

\section{References}

1. Ferlay J, Steliarova-Foucher E, Lortet-Tieulent J, Rosso S, Coebergh JW, Comber H, et al. Cancer incidence and mortality patterns in Europe: estimates for 40 countries in 2012. Eur J Cancer. 2013;49(6):1374-403.

2. Bray F, Ren JS, Masuyer E, Ferlay J. Estimates of global cancer prevalence for 27 sites in the adult population in 2008. Int J Cancer. 2013;132(5):113345.

3. Van den Beuken-van Everdingen $\mathrm{MH}$, de Rijke JM, Kessels AG, Schouten HC, van Kleef M, Patijn J, et al. Prevalence of pain in patients with cancer: a systematic review of the past 40 years. Ann Oncol. 2007;18(3):1437-49.

4. Gutgsell T, Walsh D, Zhukovsky DS, Gonzales F, Lagman R. A prospective study of the pathophysiology and clinical characteristics of pain in a palliative medicine population. Am J Hosp Pall Care. 2003;20(2):140-8.

5. Cascinu S, Giordani P, Agostinelli R, Gasparini G, Barni S, Beretta GD, et al. Pain and its treatment in hospitalized patients with metastatic cancer. Support Care Cancer. 2003;11(9):587-92.

6. Yun YH, Heo DS, Lee IG, Jeong HS, Kim HJ, Kim SY, et al. Multicenter study of pain and its management in patients with advances cancer in Korea. J Pain Symptom Manag. 2003;25(5):430-7.

7. Beck SL, Falkson G. Prevalence and management of cancer pain in South Africa. Pain. 2001;94(1):75-84.

8. Yates PM, Edwards HE, Nash RE, Walsh AM, Fentiman BJ, Skerman HM, et al. Barriers to effective 
cancer pain management: a survey of hospitalized cancer patients in Australia. Pain Symptom Manage. 2002;23(5):393-405.

9. Agency for Health Care Policy and Research, Acute Pain Management Panel: Acute pain management: Operative or medical procedures and trauma. Clinical Practice Guidelines. Washington, DC: US Department of Health and Human Service; 1992.

10. Meuser T. Symptoms during cancer pain treatment following WHO-guidelines: a longitudinal follow-up study of symptom prevalence, severity and etiology. Pain. 2001;93(3):247-57.

11. Kelsen DP, Portenoy RK, Thaler HT, Niedzwiecki $\mathrm{D}$, Passik SD, Tao Y, et al. Pain and depression in patients with newly diagnosed pancreas cancer. J Clin Oncol. 1995;13(3):748-55.

12. Warncke T, Breivik H, Vainio A. Treatment of cancer pain in Norway. A questionnaire study. Pain. 1994;57(1):109-16.

13. Sapir R, Catane R, Strauss-Liviatan N, Cherny NI. Cancer pain: knowledge and attitudes of physicians in Israel. J Pain Symptom Manage. 1999;17(4):266-76.

14. De Lima L, Sweeney C, Palmer JL, Bruera E. Potent analgesics are more expensive for patients in developing countries: a comparative study. Journal of Pain and Palliative Care Pharmacotherapy. 2004;18(1):59-70.

15. Jacobsen R, Møldrup C, Christrup L, Sjøgren P. Patient related barriers to cancer pain management: a systematic exploratory review. Sc J Caring Sci. 2009;23(1):190-208.

16. Smith MY, Winkel G, Egert J, Diaz-Wionczek M, DuHamel KN. Patient-physician communication in the context of persistent pain: validation of a modified version of the patients' Perceived Involvement in Care Scale. J Pain Symptom Manage. 2006;32(1):71-81.

17. Anderson KO, Richman SP, Hurley J, Palos G, Valero V, Mendoza TR, et al. Cancer pain management among underserved minority outpatients perceived needs and barriers to optimal control. Cancer. 2002;94(8):2295-304.

18. Berry DL, Wilkie DJ, Thomas CR, Fortner P. Clinicians communicating with patients experiencing cancer pain. Cancer Invest. 2003;21(3):374-81.

19. Coward DD, Wilkie DJ. Metastatic bone pain. Meanings associated with self-report and selfmanagement decision making. Cancer Nurs. 2000;23(2):101-8.

20. Kimberlin C, Brushwood D, Allen W, Radson E, Wilson D. Cancer patient and caregiver experi- ences: communication and pain management issues. J Pain Symptom Manage. 2004;28:566-78.

21. Jacobsen R, Sjogren P, Moldrup C, Christrup L. Physician- related barriers to cancer pain management with opioid analgesics: a systematic review. J Opioid Manage. 2007;3(4):207-14.

22. Redmond K. Organizational barriers in opioid use. Support Care Cancer. 1997;5(6):451-6.

23. Mercadante S. Opioid prescription in Italy: new law, no effect. Lancet. 2002;360(9341):1254-5.

24. De Angelis R, Sant M, Coleman MP, Francisci S, Baili P, Pierannunzio D, et al. Eurocare-5 Working Group. Cancer survival in Europe 1999-2007 by country and age: results of EUROCARE-5-a population-based study. Lancet Oncol. 2014;15(1):2334.

25. Hodes R. Cancer patients' needs and concerns when using narcotic analgesics. In: Hill CS, Fields WS, editors. Drug treatment of cancer pain in a drug-oriented society. Advances in Pain Research and Therapy, Vol. 11. New York: Raven Press; 1989. p. 91-9.

26. Sabatowski R, Arens ER, Waap I, Radbruch L. Cancer pain management in Germany - results and analysis of a questionnaire. Schmerz. 200;15(4):241-7.

27. Ensink FB, Bautz MT, Voss MC, Gorlitz A, Hanekop GG. Indicators of structural quality in palliative care for cancer pain patients in LowerSaxony. Schmerz. 2002;16(4):255-62.

28. Wu HB, Lee MC, Lai KH, Ho ST, Sun WZ, Wong JO, et al. Physicians' knowledge about pharmacological management of cancer pain - with special reference on their prescribing responses to simulated patients with cancer pain. Acta Anaesthesiol Taiwan. 2006;44(2):61-71.

29. Peker L, Celebi N, Canbay O, Sahin A, Cakir B, Uzun $S$, et al. Doctor's opinions, knowledge and attitudes towards cancer pain management in a university hospital. Agri. 2008;20(2):20-30.

30. Cleeland CS, Cleeland LM, Dar R, Rinehardt LC. Factors influencing physician management of cancer pain. Cancer. 1986;58(3):796-800.

31. Soyannwo A, Amanor-Boadu SD. Management of cancer pain - a survey of current practice in West Africa. Niger Postgrad Med. J 2001;8(4):175-8.

32. Pain \& Policy Study Group [homepage on the Internet]. University of Wisconsin-Madison: Improving global pain relief by achieving balanced access to opioids worldwide. Global Opioid Consumption, Inc.; 1998-2003 [updated 2001 Apr 11; cited 2013 Nov 8]. Available from: www.painpolicy.wisc.edu/countryprofiles. 
33. Nichol MB, Venturini F, Sung JC. A critical evaluation of the methodology of the literature on medication compliance. Ann Pharmacother. 1999;33(5):531-40.

34. Lee CR, Nicholson PW, Souhami RL, Deshmukh AA. Patient compliance with oral chemotherapy as assessed by a novel electronic technique. J Clin Oncol. 1992;10(6):1007-13.
35. Gauthier DK, Turner JG, Langley LG, Neil CJ, Rush PL. Monitoring universal precautions: a new assessment tool. Infect Control Hosp Epidemiol. 1991;12(10):597-601.

\section{Appendix}

\section{Questionnaire for patients}

1. Age:

2. Gender
A. Female
B. Male

3. Education:
A. Illiterate
B. Elementary school
C. High school
D. University

4. Family financial benefits
A. No allowances
B. $<500$ EUR
C. 500 - 1500 EUR
D. $>1500$ EUR

5. Number of household members
A. Single
B. With children
C. With husband/wife
D. With parents
E. With extended family

6. Diagnosis
A. Breast cancer
B. Colon cancer
C. Gynecological cancer
D. Lung cancer
E. Urogenital cancer
F. Melanoma
G. Head and neck cancer 
7. Does your doctor ask you about pain?
A. Always
B. Sometimes
C. Never

8. If pain is present do you report it to the doctor every time?
A. Yes
B. No

9. If the answer is NO, why do you not tell the doctor about your pain?
A. I can bear the pain
B. Because of the fear that I will not receive oncological treatment
C. Because of the fear that the disease has worsened
D. I wait for the doctor to ask me about pain

10. Do you have enough time in conversations with the doctor about pain, its causes and treatments?
A. Yes
B. No

11. If the answer is no, what you think is the most important reason for that?
A. The doctor does not have enough time
B. I do not insist on talking about pain
C. I don't know.

12. Do you know what causes your pain?
A. Yes
B. No

13. Does the doctor use a scale for pain measurement?
A. Yes
B. No

14. Does your doctor prescribe analgesics, when you mention pain?
A. Yes
B. No

15. Do you know the most important side effects of the analgesics?
A. Yes
B. No

16. Do you pay for the drugs yourself?
A. Yes
B. No 
17. How much do they cost per month of therapy?
A. $<10$ EUR
B. 10 - 25 EUR
C. $25-35$ EUR
D. 35 - 50 EUR
E. $>50$ EUR

18. Do you take the medication regularly?
A. Yes
B. No

19. If the answer is no, why do you not take the medication regularly?
A. I do not believe in medication.
B. Because of the adverse effects of the drug
C. Because the drug did not act immediately
D. Because of fear of addiction

20. Was the drug effective?
A. Yes
B. No

21. Was your doctor interested in pain reduction after treatment with analgesics?
A. Yes
B. No

22. Do you have any side effects?
A. Yes
B. No

23. Which side effects do you have?

24. Do you believe in analgesic addiction?
A. Yes
B. No

25. If you use other forms of treatment for pain, what are they?
A. Acupuncture
B. Yoga
C. Psychological treatment
D. Physical therapy
E. Propolis, honey, tea...

27. How satisfied are you with the prescribed medications?
A. Very satisfied
B. Satisfied 


\section{Slightly satisfied \\ D. Unsatisfied}

28. What is your general health like when you take analgesics?
A. Very good
B. Good
C. Moderate
D. Bad
E. Very bad

32. How satisfied are you with your doctor?
A. Very satisfied
B. Not very satisfied
C. Dissatisfied

33. Are you satisfied with education about pain treatment?
A. Very satisfied
B. Not very satisfied
C. Dissatisfied

34. Does your family participate in treatment of pain?
A. Always
B. Sometimes
C. Never

\section{Questionnaire for doctors}

1. You are a:
A. Medical oncologist
B. Radiation oncologist
C. Medical and radiation oncologist

2. Where are you working?

3. How long have you been treating oncological patients?
A. $<5$ years
B. 5 - 10 years
C. $>10$ years

4. Do you have radiotherapy in your institution?
A. Yes
B. No 
5. If the answer is no, how much does this affect treatment of pain?
A. No influence
B. Some
C. A great deal

6. How often do you ask patients about pain?
A. In $100 \%$ cases
B. $75-99 \%$ cases
C. $50-75 \%$ cases
D. $25-49 \%$
E. $0-25 \%$
F. No one

7. What is your preferred way to test intensity of pain?
A. Through conversation
B. VAS scale
C. Numerical scale
D. Macgill questionnaire
E. Other.

8. Do you ask your patients how much their therapy costs per month?
A. Always
B. Never

9. Which analgesics do you prescribe for low level pain?
A. NSAR
B. Paracetamol
C. Tramal
D. Aspirin
F. Other.

10. What do you do when a patient has strong pain initially?
A. I immediately use opioids
B. I first use weak opioids then gradually increase
C. It depends on the patient and diagnosis

11. Which is your preferred route of drug administration?
A. Oral
B. Subcutaneous
C. Intravenous
D. Intramuscular
E. Transdermal

12. Are transdermal analgesics free in your canton?
A. Yes
B. No 
14. Do you think it is necessary to improve the list of free analgesics?
A. Yes
B. No

15. Do you have an out-patients' pain clinic in your hospital?
A. Yes
B. No

16. If no, do you think that is necessary to have an out-patients' pain clinic?
A. Yes
B. No

17. Do you use adjuvant drugs for treatment of pain?
A. Yes
B. No

18. Are you interested in pain reduction after treatment with analgesics?
A. Always
B. Never

19. Do you educate patients about pain and analgesics?
B. Always
C. Sometimes, especially when the patient insists
D. Never

20. What you think is the best way to educate patients?
A. By word of mouth
B. Brochures
C. Cds
D. Other

21. Do you think that patients should receive strong opioids in the terminal phase of their illness?
A. Yes
B. It depends on their general condition and diagnosis
C. No

22. Do you think that education about pain is necessary for other medical workers than doctors?
A. Yes
B. No

23. Do you think that the bad economic situation affects treatment of pain?
A. Yes
B. No 
24. Are you satisfied with your education about pain?
A. No
B. Yes

25. How much time has passed since you had training about pain?
A. $<6$ months
B. 6-12 months
C. $>12$ months
D. I have never had any education about pain

26. If you use some nonmedical forms of treatment of pain, they are: 